\title{
Product Innovation, Process Innovation And COMPETITIVE LESSONS FROM CONSUMER ELECTRONICS INDUSTRY
}

\author{
Milivoj Markovic, Nikola Draskovic \& Vladimir Gnjidic
}
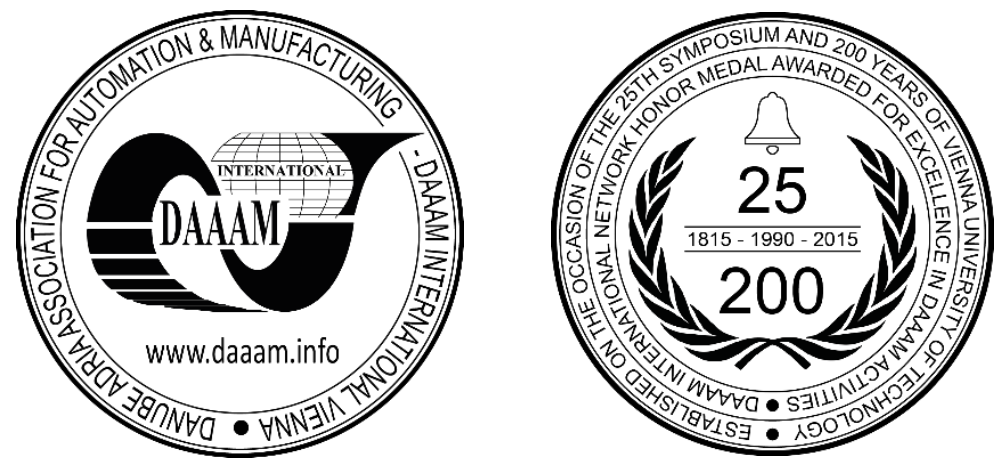

This Publication has to be referred as: Markovic, M[ilivoj]; Draskovic, N[ikola] \& Gnjidic, V[ladimir] (2018). Product Innovation, Process Innovation and Competitive Lessons from Consumer Electronics Industry, Proceedings of the 29th DAAAM International Symposium, pp.0004-0008, B. Katalinic (Ed.), Published by DAAAM International, ISBN 9783-902734-20-4, ISSN 1726-9679, Vienna, Austria

DOI: $10.2507 / 29$ th.daaam.proceedings.001

\begin{abstract}
With the introduction of iPhone, Apple reinvented the mobile phone industry and set new standards in how the smartphones of the future should look like and what should they be capable of. It was at the time considered the pinnacle of smartphone layout and capabilities. As time has shown, it was in a sense quite the opposite, a beginning of the new cycle of product innovation. With first iPhone, Apple has set the design standard for all the future smartphones. As the product innovation gradually subsided, process innovation has increased. Future generations of iPhones have featured, on average, less and less product innovation, especially in product architecture but an increase in the performance of previous features. Additionally, new competitors have started to enter the industry with branded smartphones that in appearance have mimicked the standard set by Apple iPhone. In order to raise barriers to entry and shield off the competition, Apple shifted the competitive battlefield from the devices itself (already exhausted possibilities for product innovation and process innovation) to the (eco)system level. This paper analyses the development of Apple ecosystem and its main challenger Android ecosystem and explores competitive implications of their rivalry.
\end{abstract}

Keywords: Apple; product innovation; process innovation; Android; ecosystem

\section{Introduction}

Nothing in business ever stands still, leading products are replaced with new and improved versions, companies are outperformed by superior competitors, and industries are replaced by other industries. In such a turbulent environment, what can managers do to improve their chances for success? Managerial literature offers a number of tools that might inform managers about the best course of action to undertake in order to outperform the competitors and finish on the top of the performance charts.

Management tools are readily available to everyone; hence how could they convey competitive advantage then? The true mastery comes not from using the tools but from interpreting the real timing of events that the tools suggest. Management of companies in a competitive environment was and will be a mix of science and intuition for every manager.

Consumer electronics industry in general and smartphone industry in particular had a number of changes throughout its existence.Hardly all of them can be called revolutionary changes or disruptive as modern business jargon suggests. 
However, every once in a while a change happens that reshuffles the rules of the game, that changes Key Success Factors (KSF). A major change often times leaves incumbent managers of guard and creates an opportunity for an agile (new) competitors to appropriate a huge amount of value with their innovative products. Incumbent managers need not be "sleepy" in their success, they may be too focused on exploiting their strengths and come late up the curve of a new innovation cycle and find their companies as late entrants into the changed competitive landscape.

This paper aims to apply management tools in analyzing the dynamics of the smartphone industry in order to show their usefulness for devising strategy. Additionally, it will provide managers with recommendations on how to compete for the sake of achieving competitive advantage in this dynamic and fast changing industry. Smartphone industry is a multibillion-dollar industry and with increase of functionality of the smartphones the future of the industry looks to be on the growth path, hence it is of great importance and value to understand the most probable pathways of industry development.

\section{Industry Dynamics}

Industries do not follow a linear development path. Dominantly underpinned by changes in consumer tastes (demand side) and innovation on the producer end (supply side), industries tend to enter into theoretically predictable cycle of changes that can usefully be described by a well-known concept of Industry Life Cycle curve (ILC) [1] [2]. Supply and demand side trends tend to exert joint effect on the industry dynamics once the innovation cycle is started. Industry Life cycle curve is most commonly divided into four distinct phases based on the overall industry revenue growth changes: Introduction, Growth, Maturity, and Decline.

For technology products, product innovation is the most common moment that defines the shift in the stability of the industry dynamics, it can even mark the emergence of completely new industries, hence the reason why product innovation marks the beginning of the Introduction phase. Product innovation in its essence marks the emergence of a new product or at minimum a substantial change of the existing product [3] [4]. Firms have a vested interest in pursuing product innovation since it has been well documents in the literature that product innovation is related to improved performance, for both small and large firms [5] [6]. In the introduction phase companies tend to establish competitive advantage based on the technical leadership of their innovative product. Price of the new products tends to be very high as early adopters are usually less price sensitive and are willing to pay premium for the newest gadget available. High price of innovative product with fast pace product change (key factor for establishing competitive advantage in this phase) makes the market for innovative product on average relatively small and leads companies to differ larger investments in production capacity. Hence, manufacturing is usually based on small scale. Main competitors in this phase tend to be technology leaders which possess superior technology, usually through high investment in their R\&D capacity.

While transition between adjacent phases of ILC does not happen at a discrete and single moment in time, there are events that can be identified (usually with hindsight) for which a plausible case can be made that they have marked the shift from one phase to another. Transition from Introduction phase into Growth phase tends to be identified with establishing of dominant design [7]. A dominant design is a consequence of convergence of industry around very similar (dominating) product architecture which for various reason shows a clear superiority versus competing designs which were experimented with in the Introductory phase [8]. This convergence establishes a stability in product architecture and is a necessary prerequisite for rapid growth phase. Identifying the emergence of dominant design (decrease of product innovation), technology leaders feel more confident (less risky) to invest into manufacturing capacity for large scale production. This leads to price fall since standardized production inevitably leads to lower cost of productions. Lower prices lead to growth in sales (hence the Growth phase). As product innovation subsides, refinement of product design leads to improved quality and greater variety of products. One of the hallmarks of Growth phase is emphasis on Process Innovation since it provides a key base for establishing competitive advantage [9]. Competitors who lag behind the market leaders in investing in process technology and subsequently show lower growth rates than market leaders, tend to exit the market either through filing for bankruptcy of by being acquired by larger and more successful (faster growing) competitors.

When it comes to technology products, there is well established link between innovation and location [10] [11]. Product innovation usually occur in clustered environment such as technology parks or in geographical clusters [12], most famous being Silicon Valley where an infrastructure of high tech companies, cutting edge universities and venture capital exist. However, such clusters are not the cheapest environments for mass scale standardized production. This leads to a well recognizable and established trend among market leaders in the growth phase, and that is to seek environments with low cost and locate their manufacturing there. Since production cost is increasingly more important for achieving competitive advantage in this phase, companies tend to outsource their production in locations quite distant from their innovation hub [13] [14].

The Growth phase, driven by popular appeal for a novel product, coupled with ever decreasing price and improvement in quality, although a strong marketing proposition, has its limitations. Once a high market penetration is achieved during the Growth phase, there are no larger pockets of uncontested marketplace left. The consumers are quite knowledgeable about the product and the product has somewhat decreased in its perceived social prestige status, all of which makes consumers increasingly price sensitive [15] [16]. 
Most of the consumers already own the product and demand fluctuations are mostly determined by repeat purchasing where consumers replace older version of the product with a new version. Differentiation based on technology has a low probability of success while differentiation based on brand recognition offers a more stable basis for strategy development. Competitive pressure is the highest yet.

Emergence of these conditions clearly signals that Industry has entered the Mature phase of its ILC. One of the hallmarks of mature industries is commoditization of the industry products where consumers perceive products to be more similar to each other than in any of the previous phases [17]. This puts additional pressure on competitors as consumers more and more base their choices on price. Competitive pressures and cost-based competition tend to primarily impact small scale (small market share) competitors. They lack sufficient size needed to achieve low average cost [18] and with low (if any) market growth, there competitive position is untenable. Hence industry consolidation at this point tends to be strong, where all other things being equal, competitors with larger market shares have the best competitive starting position [19].

If the Industry does not enter into another phase of innovation, it will most likely enter into a Decline phase as its products face inevitable obsolescence. With ever smaller demand overcapacity grows and competitive pressures increase. The easing of competitive pressures mostly arises from bankruptcies and exists from the industry. Competitors tend to decrease the scope of their product lines and mainly focus on products that are mainstream and profitable.

Previous paragraphs have described a theoretical path that is not necessarily the truest description of how all technology industries development paths looks like. For example, the mobile apps industry follows the common pattern, but with less predictable shifts between the lifecycle phases [20]. This theoretical path is informative as it points to the most important factors to consider when devising a strategy for today as well as for the future. Industry Life Cycle curve rests on substantial empirical support and mangers would be advised to learn from the past for more prosperous future. Although it can be applied in it's here described form on various technology industries, it usability is most likely the greatest for industries that are in early stages of their development as well as for the ones that have a history of product innovation underpinning their dynamics. Many industries have gone through many cycles of innovation and maturity, such as TV industry of telephone industry, each one started by technology innovation.

Our effort in this paper are focused on demonstrating the usability of ILC analysis for smartphone industry development path analysis. It is a global technology industry characterized by high levels of innovation which provides an excellent environment for testing the key tenants of ILC curve as described previously.

\section{Case Study: Smartphone Industry}

\subsection{Industry evolution}

Handheld mobile devices for communication have existed for decades. First handheld mobile device was a creation of Martin Cooper and his Motorola team in 1973 [21]. In the following decades mobile phones have gradually expanded, initially from developed countries and primarily from urban areas into a worldwide everyday utility used by billions of people. Today's mobile phones barely resemble their decades old ancestors, both in appearance (design) and in functionality. With the progress of technology (diffusion and dissemination of knowledge) mobile phones and the respective industry changed, sometimes gradually, and on occasions radically [22]. Different product innovations have primarily been responsible for shifts in industry growth rates.

Smartphones can be considered the latest generation of handheld mobile devices. As the name suggests, these devices are primarily computing devices with various types of communication capabilities. First handheld mobile device that is considered a forerunner to smartphone was IBM Simon introduced in 1994 [23]. It marked the merger (convergence) of different technologies into a single (mobile device). Various mobile devices existed previously that provided various computing capabilities (calendars, to-do lists, etc.) but without communication capabilities. IBM Simon was the first to bridge the gap. The first device marketed as a "smartphone" was Ericsson Smartphone R380 introduced in 2000, featuring Symbian operating system and touchscreen utilized with a stylus [24].

Later years marked the introduction of various different devices that substantially differed from existing ones both by functionality and especially design. Nokia was known for its Communicator series of smartphones that opened in clamshell format. BlackBerry was a household name with its "berry-like" design of the exterior featuring fully open physical QWERTY keyboard. Many others devices used different designs such as Slider designs op some Nokia models.

Landmark change in industry happened in 2007 when Apple (a newcomer to the industry) introduced its first smartphone, the iPhone. The launch slogan was farsighted: "Apple Reinvents the Phone with iPhone" [25]. It featured multiple changes from competing devices, most readily visible in design. It had a slate plate design with multi-touch touchscreen and with only one button on the front side, a revolutionary difference in comparison to industry incumbents like previously mentioned Nokia and BlackBerry. Next to design features, functional features also differed substantially from the competing smartphones. It used a proprietary operating system developed by Apple, the iOS. Less than a year later since the launch of first iPhone, Apple introduced the App Store, a digital distribution platform where third-party software developers could market the apps they developed. Subsequent generations of iPhone basically kept the key design outline with incremental improvements. Functionality features were gradually added like Touch ID, Apple fingerprint recognition technology, with gradual improvement of existing features [26]. 
Samsung, an incumbent in the mobile phone industry, introduced its first of the Galaxy series smartphones in 2009. It was based on Android operations software developed by Google [27]. In design outline to a large degree it resembled iPhone design. Apps were available for download through Google Play, a digital platform operated by Google.

Samsung as well as Apple have gradually diversified their smartphone offering through introduction of a different models that are differentiable primarily by size and functionality. More advanced versions come at a price premium and are oriented toward business and high-end users. These can be considered as technology leaders on smartphone market. Other smartphone models by the two companies are targeting mostly midrange segment with lower functionality and simpler materials used for design.

Throughout the years' other companies have entered the smartphone market (i.e. Huawei, HTC), initially competing on price in the middle and lower end segment of the market but gradually with time toward establishing a presence in the upper market segments. On the other hand, many household brands from the pre-smartwatch era have witnessed substantial loss of their market shares, primarily to Apple and Samsung. The two companies have with time introduced other hardware devices that complement their smartphone offering, specifically smartwatches.

\subsection{Discussion}

Analyzing the changes that smartphone industry has went through in the last two decades there are many salient events that ILC curve can explain and even predict with reserves when it comes to exact timing of the changes. Many of the changes are phased in nature and there is no single event or a discrete moment in time that would clearly mark the industry shift hence mangers should exercise caution when changing their strategies in order to cope with different industry environment.

It is clear that in the early days of the industry there was a substantial diversity among the smartphone models, product innovation was high and it was driving the industry change. Early adopters were mostly business users and technology savvy individuals. Rate of change was rather fast with substantial differences between subsequent models of the smartphones. Key competitors were mostly competing by adding new features and increasing the functionality of the smartphone. This was clearly the time of the introductory phase of the ILC curve.

With iPhone, Apple established what could be called a dominant design which marked the shift from the Introductory phase to a Growth phase. Dominant design established a slate design with single button on the front side and a large touchscreen as a standard that would still be in use, with minor modifications, more than a decade later. Establishing dominant design enabled larger investments in production and manufacturing capabilities and focus on efficiency which decreased the price and expanded the market. The focus has gradually started to shift from product innovation toward process innovation and the rate of product innovation was gradually decreasing. The focus of key competitors was in general more on improvement of existing features with the dominant design then on adding new features. New competitors, low end ones, have gradually started to emerge and enter the industry while many incumbents from presmartphone era have witnessed loss of their market share and exited the market.

One might claim that smartphone industry is currently in the mature phase of the ILC curve. Market is to a large degree saturated with majority of the purchases coming from existing buyers replacing their older versions of the smartphone. Customers have become more knowledgeable about the product and subsequently more price sensitive. At the same time, different models/brands of smartphone are more similar to each other than in any of the previous phases of ILC. Coupled with consumer focus on prices, these factors mandate that producers place stronger than ever emphasis on cost of production as one of the main drivers of profitability. Competition is greater than ever especially on the lower end of the market as the effects of commoditization have made it increasingly harder to differentiate.

Will this industry enter the decline phase? When it will enter decline phase? Considering the current developments of the industry, there is a clear trend of convergence between the multiple functionalities of different technology/communication devices. Crossover devices such as phablets (combination of phone and tablet) are present on the market for some time. Will this be the new direction of the industry development and prevent the smartphone industry from shifting toward stagnation and eventually decline? These and many similar questions are definitely on the agenda of industry incumbents. Confronted with the dilemma of competing in the mature/stagnating or even declining industry or in an industry with strong growth perspectives, incumbents know that they must be either radical innovators or fast followers. Technology industries do not provide a lot of rewords for laggards.

\section{Conclusion}

This paper reviews and analyses the (r)evolutionary development of smartphone industry using the Industry Life Cycle curve through a vast body of research available to explain and predict the developments of the industry. It is visible that smartphone industry went through many of the standard phases of the industry development as predicted by the ILC curve with the key events (strong product innovation, emergence of the dominant design, shift of focus on process innovation and subsequent commoditization).

This not only provides an explanation of the industry's past but it also provided a base for prediction future structure of the industry and key competitive factors. It also proves the usability and value of a classic tool of strategy analysis, the Industry Life Cycle curve. The classical model underpinned with new empirical research provides a strong tool for managers in developing competitive strategies for today as well for tomorrow. 
Limitations of this paper are that if focuses on only one segment of consumer electronics industry, namely the smartphone industry. Further research should seek to show the usefulness of these and other tools of strategy analysis on other segments of consumer electronics industry (television, smartwatches, tablets, etc.).

\section{References}

[1] Aherne, A. (2006). Exploit the Levitt Write Cycle. Journal of Strategic Marketing, 14, 1, 77-87.

[2] Levitt, T. (1965). Exploit The Product Life Cycle. Harvard Business Review, 43, 6, 81.

[3] de Jong, J. P. J., \& Vermeulen, P. A. M. (2006). Determinants of product innovation in small firms: A comparison across industries. International Small Business Journal, 24, 6, 587-609.

[4] Di Benedetto, C. A. (1999). Identifying the key success factors in new product launch. The Journal of Product Innovation Management, 16, 6, 530-544.

[5] Banbury, C. M., \& Mitchell, W. (1995). The Effect of Introducing Important Incremental Innovations on Market Share and Business Survival. Strategic Management Journal, 16, S1, 161-182.

[6] Vermeulen, P. A. M., De Jong, J. P. J., \& O'Shaughnessy, K. C. (2005). Identifying key determinants for new product introductions and firm performance in small service firms. The Service Industries Journal, 25, 5, 625-640.

[7] Utterback, J. M., \& Abernathy, W. J. (1975). A dynamic model of process and product innovation. Omega, 3, 6, 639-656.

[8] Anderson, P., \& Tushman, M. L. (1990). Technological Discontinuities and Dominant Designs: A Cyclical Model of Technological Change. Administrative Science Quarterly, 35, 4, 604-633.

[9] Schallmo, D. R. A., Brecht, L., \& Ramosaj, B. (2018). Process Innovation: Enabling Change by Technology: Basic Principles and Methodology: A Management Manual and Textbook with Exercises and Review Questions. Berlin, Heidelberg: Springer Berlin Heidelberg.

[10] Ferreira, J. J. M., Fernandes, C. I., \& Raposo, M. L. (2017). The Effects of Location on Firm Innovation Capacity. Journal of the Knowledge Economy, 8, 1, 77-96.

[11] Ubeda, F., Ortiz-de-Urbina-Criado, M., \& Mora-Valentín, E.-M. (2018). Do firms located in science and technology parks enhance innovation performance? The effect of absorptive capacity. The Journal of Technology Transfer, 128.

[12] He, J., \& Fallah, M. H. (2014). Dynamics of Inventor Networks and the Evolution of Technology Clusters. International Journal of Urban and Regional Research, 38, 6, 2174-2200.

[13] Bengtsson, L., Von Haartman, R., \& Dabhilkar, M. (2009). Low-Cost versus Innovation: Contrasting Outsourcing and Integration Strategies in Manufacturing. Creativity and Innovation Management, 18, 1, 35-47.

[14] Fifarek, B. J., Veloso, F. M., \& Davidson, C. I. (2008). Offshoring technology innovation: A case study of rare-earth technology. Journal of Operations Management, 26, 2, 222-238.

[15] Goldsmith, R. E., Flynn, L. R., \& Kim, D. (2010). Status Consumption and Price Sensitivity. Journal of Marketing Theory and Practice, 18, 4, 323-338.

[16] Han, S., Gupta, S., \& Lehmann, D. R. (2001). Consumer price sensitivity and price thresholds. Journal of Retailing, 77, 4, 435-456.

[17] Reimann, M., Schilke, O., \& Thomas, J. S. (2010). Toward an understanding of industry commoditization: Its nature and role in evolving marketing competition. International Journal of Research in Marketing, 27, 2, 188-197.

[18] Boulding, W., \& Staelin, R. (1993). A Look on the Cost Side: Market Share and the Competitive Environment. Marketing Science, 12, 2, 144-166.

[19] Deans, G. K., Kroeger, F., \& Zeisel, S. (2002). The consolidation curve. Harvard Business Review, 80, $12,20$.

[20] Draskovic, N., Markovic, M. and Znidar, K. (2018) Product lifecycle strategies in digital world. International Journal of Management Cases, 20, 3, 29-43.

[21] International Business Times. (2013, April 3). The Cell Phone Celebrates 40 Years: Marty Cooper's First Call Was to Brag. International Business Times. http://search.ebscohost.com.ezproxy.rit.edu/login.aspx?direct=true \&db=bwh\&AN=453262.20130403\&site=ehostlive

[22] Grant, R. M. (2013). Contemporary strategy analysis (8th ed.). Chichester;Hoboken, N.J;: Wiley.

[23] D. O. (2009). The evolution of the mobile entrepreneur. Entrepreneur, 37(8), 31. Retrieved: September 26, 2018, from: http://search.ebscohost.com.ezproxy.rit.edu/login.aspx?direct=true \&db=bsh\&AN=47106350\&site=ehostlive

[24] MobilityArena. (2012, January 24). Ericsson R380 - The First Smartphone? Retrieved from MobilityArena: https://mobilityarena.com/ericsson-r380-the-first-smartphone/

[25] M2PressWIRE (2007) “Apple reinvents the phone with iPhone". Retrieved: September 26, 2018, from http://search.ebscohost.com.ezproxy.rit.edu/login.aspx?direct=true \&db=nfh\&AN=16PU709281491\&site=ehostlive.

[26] Husnjak, S[inisa]; Perakovic, D[ragan]; Forenbacher, I[van] \& Jovovic, I[van] (2016). Identification and Prediction of User Behavior Depending on the Context of the Use of Smart Mobile Devices, Proceedings of the 26th DAAAM International Symposium, pp.0462-0469, B. Katalinic (Ed.), Published by DAAAM International, ISBN 978-3902734-07-5, ISSN 1726-9679, Vienna, Austria DOI: 10.2507/26th.daaam.proceedings.061

[27] Nystedt, D. (2009) "Samsung Unveils Its First Google Phone”, PCWorld, Retrieved: September 20, 2018, from: https://www.pcworld.com/article/163874/Samsung_Unveils_Its_First_Google_Phone.html 